\title{
Societal and health care benefits of early use of inhaled steroids
}

\author{
Tari Haahtela, Timo Klaukka
}

In this issue of Thorax Blais et $a l^{1}$ report results from a population based register study which show that first regular treatment with inhaled corticosteroids initiated in the year following the recognition of asthma can reduce by up to $80 \%$ the risk of a hospital admission for asthma compared with regular treatment with theophylline. It is a dramatic result, albeit not so surprising. Regular use of inhaled steroids prevents exacerbations of asthma, ${ }^{2}$ fatal and near fatal episodes of asthma, ${ }^{3}$ and accelerated loss of lung function. ${ }^{4}$ From 1985 to 1993 anti-inflammatory treatment with inhaled steroids decreased the number of hospital days per year in Swedish children to less than a third. ${ }^{5}$ In a large community sample in eastern Massachusetts inhaled steroids halved the risk of admission to hospital in each severity group. ${ }^{6}$ The data strongly supported the early prescription of inhaled steroids. In contrast, overconfidence in $\beta_{2}$ agonists combined with suboptimal use of inhaled steroids increased the risk of admission to hospital fivefold in Belgium.?

Hospital admission for asthma is a marker of severe and uncontrolled disease and indicates an increased risk of a subsequent fatal attack. ${ }^{8}$ The cost of hospital admissions represents $25-50 \%$ of the total costs for asthma, depending on whether the calculations include only direct medical costs or the additional indirect costs caused mainly by loss of production..$^{910}$ Thus, a decrease in hospital admissions would reflect improved disease control, meaning less human suffering and great savings for society.

However, real life is agonising and significant undertreatment still prevails in Canada, for instance. ${ }^{11}$ In France, Bousquet et $a l^{12}$ reported significant undertreatment of severe asthma- $85 \%$ of patients living in Paris and $60 \%$ in Montpellier were not receiving any anti-inflammatory treatment. Ferrante et $a l^{13}$ found that inhaled antiinflammatory drugs were insufficiently used in young men in Italy with only $16 \%$ of those with bronchial obstruction using inhaled steroids or cromolyn sodium. Changes in treatment practices are slow. In Denmark Gaist et $a l^{14}$ selected from a nationwide register those asthmatic subjects who used more than 1600 inhalations per year of $\beta_{2}$ agonists. In $199133 \%$ of them did not use inhaled steroids. When the survey was repeated in 1994 the situation had not improved, with $37 \%$ still not using inhaled

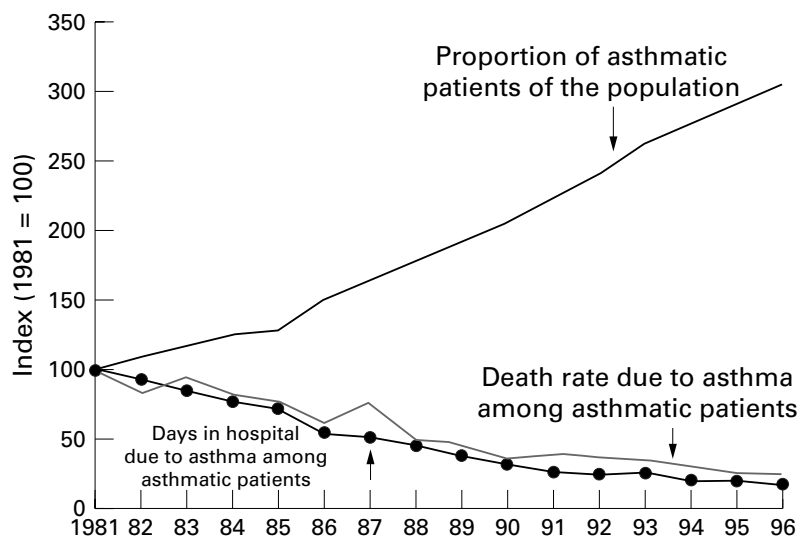

Figure 1 Asthma statistics in Finland for the period 1981-1996 showing a relative increase in the number of patients entitled to special reimbursement for their drug costs and decreases in the death rate and days in hospital for these patients (index, $1981=100$ ). steroids. In 1991 the new US guidelines promoted earlier use of anti-inflammatory medication, ${ }^{15}$ but in Philadelphia a gap between optimal asthma drug prescribing and actual patterns widened from 1991 to $1993 .{ }^{16}$ Underuse of inhaled steroids was closely associated with lower educational attainment. In East London Griffiths et $a l^{17}$ observed that practices prescribing lower ratios of prophylactic anti-inflammatory medication to bronchodilator medication had higher hospital admission rates.

The study by Blais et $a l^{1}$ does not only address the benefits of inhaled steroids but, most importantly, the early use of them; during the first year of treatment subjects initially or subsequently treated with inhaled steroids were $40-80 \%$ less likely to be admitted to hospital for asthma than regular users of theophylline. Although the treatment was new for the patients, the disease may have already had a prolonged course since only regular use of inhaled steroids, rather than irregular use, protected against the first admission to hospital. The diagnosis of asthma is often severely delayed, which has an influence on the prognosis and on the efficacy of therapeutic interventions. ${ }^{18}$

At the moment most international guidelines recommend anti-inflammatory medication, preferably with inhaled steroids, as first line treatment to gain control of the disease as fast as possible. There is no doubt that early use of inhaled steroids has a substantial impact on morbidity. However, very few studies have addressed the long term influence of these drugs. Usually the beneficial effects gradually disappear when the treatment is withdrawn. Only one study has indicated that, in patients with newly diagnosed asthma, early intervention with an inhaled steroid may lead to long term remission and preserve lung function better than treatment with a $\beta_{2}$ agonist. $^{19}{ }^{20}$ Although we lack evidence that the use of inhaled steroids, or any other pharmacological intervention, changes the natural course of asthma, their invaluable short term effects justify their introduction as soon as the diagnosis of asthma is established. However, the fear of steroids - deep in the public as well as in the medical society-and their lack of immediate efficacy compared with $\beta_{2}$ agonists, together with the relative cost, are obstructing their appropriate use.

In Finland the consumption of short acting $\beta_{2}$ agonists has been stable for several years while the use of inhaled steroids continues to increase. In 1996 the ratio of prescriptions of preventive anti-asthmatic medication to $\beta_{2}$ agonists exceeded 1.0 in Finland as the first Nordic country. ${ }^{21}$ From the beginning of the 1990 s much emphasis has been put on the early detection of asthma and the introduction of inhaled steroids as first line treatment for all asthmatic patients except, perhaps, small children. Simple and cost effective self-management programmes based on adjusting the dose of regular inhaled steroids according to symptoms and home monitoring of peak flow values were also developed. ${ }^{22}{ }^{23}$ This policy was strengthened by the national Asthma Programme launched in $1994 .^{24}$ The Programme was implemented efficiently at a local level and one doctor and one nurse in each health centre were appointed to take charge of know-how and quality of asthma treatment as well as of patient education.

Several indicators show that active treatment of asthma in primary care supported by specialists in secondary care 
has been successful, and the burden of the disease on society is decreasing in spite of an increase in its occurrence. In 1981 the Finnish Social Insurance Institution recorded 49259 asthma patients who were entitled to special reimbursement for their drug costs. In 1996 the figure had increased about threefold to 159105 patients (population 5.1 million). Nevertheless, days in hospital per asthmatic population in 1996 were only one quarter of that in 1981, and mortality due to asthma showed a similar trend (fig 1). Although several factors have probably contributed to the positive trends-even the disease may have become milder-early treatment of asthma with inhaled steroids deserves much credit for this favourable development.

TARI HAAHTELA TIMO KLAUKKA

Department of Allergology, Helsinki University Central Hospital, PO Box 160 00029 Huch, Finland

and

The Social Insurance Institution,

Helsinki,

Finland

1 Blais L, Suissa S, Boivin J-F, et al. First treatment with inhaled corticosteroids and the prevention of admissions to hospital for asthma. Thorax 1998;53:0000-0.

2 Juniper EF, Kline PA, Vanzielegheim MA, et al. Effect of long-term treatment with an inhaled corticosteroid (budesonide) on airway hyperresponsiveness and clinical asthma in nonsteroid-dependent asthmatics. Am Rev Respir Dis 1990;142:832-6.

3 Ernst P, Spitzer WO, Suissa S, et al. Risk of fatal asthma and near-fatal asthma in relation to inhaled corticosteroid use. fAMA 1992;268:3462-4.

4 Dompeling E, van Schayk CP, van Grunsven PM, et al. Slowing the deterioration of asthma and chronic obstructive pulmonary disease observed during bronchodilator therapy by adding inhaled corticosteroids: a 4-year proing bronchodilator therapy by adding inhaled cortic

5 Wennergren G, Kristjánsson S, Strannegård I-L. Decrease in hospitalization for treatment of childhood asthma with increased use of antiinflammatory treatment, despite an increase in the prevalence of asthma. $\mathcal{F}$ Allergy Clin Immunol 1996;97:742-8.
6 Donahue JG, Weiss ST, Livingston JM, et al. Inhaled steroids and the risk of hospitalization for asthma. $\mathscr{F} A M A$ 1997;277:887-91.

7 Van Ganse E, Hubloue I, Vincken W, et al. Actual use of inhaled corticosteroids and risk of hospitalisation: a case-control study. Eur $\mathcal{F}$ Clin Pharmacol 1997;51:449-54.

8 Crane J, Pearce N, Burgess C, et al. Markers of risk of asthma death or readmission in the 12 months following a hospital admission for asthma. Int 7 Epidemiol 1992;21:737-44.

9 Weiss KB, Gergen PJ, Hodgson TA. An economic evaluation of asthma in United States. N Engl f Med 1992;326:862-6.

10 Haahtela T, Terho EO, Hannuksela M, et al. Occurrence of allergy and its economical impact (in Finnish). In: Haahtela T, Hannuksela M, Terho EOT, eds. Allergologia. Helsinki: Duodecim, 1993: 19-29.

11 O'Byrne PM, Cuddy L, Taylor DW, et al. The clinical efficacy and cost benefit of inhaled corticosteroids as therapy in patients with mild asthma in primary care practice. Can Respir f 1996;3:169-75.

12 Bousquet J, Knani J, Henry C, et al. Undertreatment in a nonselected population of adult patients with asthma. F Allergy Clin Immunol 1996;98:51421.

13 Ferrante E, Muzzolon R, Fuso L, et al. Bronchial asthma: still an inadequately assessed and improperly treated disease. F Asthma 1994;31: $117-21$

14 Gaist D, Hallas J, Hansen N-CG, et al. Are young adults with asthma treated sufficiently with inhaled steroids? A population-based study of prescription data from 1991 and 1994. Br f Clin Pharmacol 1996;41:285-9.

15 Guidelines for the Diagnosis and Management of Asthma. Publication 91-3042. Washington, DC: US Department of Health and Human Services, 1991.

16 Lang DM, Sherman MS, Polansky M. Guidelines and realities of asthma management. The Philadelphia story. Arch Intern Med 1997;157:1193-200.

17 Griffiths C, Naish J, Sturdy P, et al. Prescribing and hospital admissions for asthma in east London. BMF 1996;312:481-2.

18 Haahtela T. Early treatment of asthma. Allergy 1998 (in press).

19 Haahtela T, Järvinen M, Kava T, et al. Comparison of a $\beta_{2}$-agonist, terbutaline, with an inhaled corticosteroid, budesonide, in newly detected asthma. N Engl F Med 1991;325:388-92.

20 Haahtela $T$, Järvinen $M$, Kava $T$, et al. Effects of reducing or discontinuing inhaled budesonide in patients with mild asthma. N Engl f Med 1994;331: $700-5$.

21 Nordic Statistics on Medicines 1993-1995. NLN Publication No 43. Uppsala: Nordic Council on Medicines, 1996.

22 Lahdensuo A, Haahtela T, Herrala J, et al. Randomised comparison of self management and traditional treatment of asthma over one year. BMF 1996;312:748-52.

23 Lahdensuo A, Haahtela T, Herrala J, et al. A cost effectiveness analysis of guided self management of asthma in Finland. BM7 1998;316:1138-9.

24 Asthma Programme in Finland 1994-2004. Ministry of Social Affairs and Health. Clin Exp Allergy 1996;Suppl 1:1-24. 